\title{
Applications of Lithium-Ion Batteries in Grid-Scale Energy Storage Systems
}

\author{
Tianmei Chen ${ }^{1} \cdot$ Yi Jin $^{1} \cdot$ Hanyu $\mathrm{Lv}^{2} \cdot$ Antao Yang $^{2} \cdot$ Meiyi Liu ${ }^{1} \cdot$ Bing Chen ${ }^{1} \cdot$ Ying Xie $^{1} \cdot$ Qiang Chen $^{2}$
}

Received: 7 December 2019 / Revised: 26 December 2019 / Accepted: 10 January 2020 / Published online: 8 February 2020

(c) The Author(s) 2020

\begin{abstract}
In the electrical energy transformation process, the grid-level energy storage system plays an essential role in balancing power generation and utilization. Batteries have considerable potential for application to grid-level energy storage systems because of their rapid response, modularization, and flexible installation. Among several battery technologies, lithium-ion batteries (LIBs) exhibit high energy efficiency, long cycle life, and relatively high energy density. In this perspective, the properties of LIBs, including their operation mechanism, battery design and construction, and advantages and disadvantages, have been analyzed in detail. Moreover, the performance of LIBs applied to grid-level energy storage systems is analyzed in terms of the following grid services: (1) frequency regulation; (2) peak shifting; (3) integration with renewable energy sources; and (4) power management. In addition, the challenges encountered in the application of LIBs are discussed and possible research directions aimed at overcoming these challenges are proposed to provide insight into the development of grid-level energy storage systems.
\end{abstract}

Keywords Lithium-ion batteries · Grid-level energy storage system · Frequency regulation and peak shaving $\cdot$ Renewable energy integration $\cdot$ Power management

\section{Introduction}

Electrical energy plays a dominant role in industrial development, urbanization, and economic advancement, as well as in our daily life. However, given that the demand for electricity is fluctuating, imbalance between power generation and utilization often occurs. Moreover, to reduce carbon emission, the associated climate change, and the issues of energy supply shortage, electrical energy generation around the world, which is accompanied by the development of some renewable energy sources, is undergoing significant changes. Therefore, the instantaneous demand for electrical energy and unpredictable daily and seasonal variations of demand pose serious challenges to the power network during energy generation, transmission, and distribution. In practical use, such as in the electrical energy conversion

Tianmei Chen

Diphorse@126.com

1 State Grid Zhejiang Zhedian Tendering Consulting Co., Ltd., Zhejiang 310000, China

2 State Grid Zhejiang Procurement Company, Zhejiang 310000, China process, the grid-level energy storage system converts electricity from the electrical energy generation network into a storable form and converts it back into electrical energy once needed, which is considered a desirable technology to deal with the aforementioned challenges [1]. As a just-in-time supply system, grid-level electrical energy storage systems have been employed to support a wide range of applications from power generation to transmission and large-scale electronic devices. For stationary application, grid-level electrical energy storage systems store the excess electrical energy during peak power generation periods and provide the vacant power during peak load periods to stabilize the electric power systems by load leveling and peak shaving $[2,3]$. In addition, the energy storage system can balance the load and power of the grid network by charging and discharging to provide regulated power to the grid with a fast response time. The energy storage system can also help establish a sustainable and low-carbon electric pattern that is achieved using intermittent renewable energy efficiently. Moreover, as a power monitoring network, the power grid system could predict/diagnose the failure to identify irregularities/weak points in time. 
To date, several energy storage systems, including hydroelectric power, capacitors, compressed air energy storage, flywheels, and electric batteries, have been investigated as enablers of the power grid [4-8].

Among these energy storage systems, electric batteries exhibit considerable potential for application to grid-level electrical energy storage because of their attractive features, such as flexible installation, modularization, rapid response, and short construction cycles $[9,10]$. Generally, when electric batteries are applied to the grid-level energy storage system, battery technologies are required to satisfy complex and large-scale deployment applications to the power grid. Therefore, the requirements for grid energy storage applications, such as capacity, energy efficiency (EE), lifetime, and power and energy densities, should be considered. In addition, batteries applied to grid-level energy storage systems need to be analyzed in terms of grid services, including frequency regulation, peak shaving, load leveling, and largescale integration of renewable energies.

Among various battery technologies, lithium-ion batteries (LIBs) have attracted significant interest as supporting devices in the grid because of their remarkable advantages, namely relatively high energy density (up to $200 \mathrm{Wh} / \mathrm{kg}$ ), high EE (more than 95\%), and long cycle life (3000 cycles at deep discharge of $80 \%$ ) [11-13]. Thus far, $77 \%$ of electrical power storage systems in the USA that operate to stabilize the grid (e.g., primarily for regulating frequency) rely on LIBs, indicating a high-value market for LIBs [11].

In addition, given their high energy density, LIBs will be an ideal choice for integration with renewable energy sources in grid-level energy storage systems, in which LIBs store the generated electrical energy for use with a minimal cost to end consumers when demanded [14]. In recent years, LIBs have been successfully developed, with remarkable improvements in performance [15-17]. Various excellent review articles have focused on the fundamentals and investigation of LIBs, which will not be discussed in detail in the present perspective, and interested readers that hope to obtain further details can refer to previously reported studies [18-21]. However, a few studies focused on the applications of LIBs to grid-level energy storage systems that depend on specific application requirements of grid-scale energy storage, including frequency regulation, peak shaving, load leveling, large-scale integration of renewable energies, and power management.

Herein, in this perspective, LIBs serving as promising energy storage technology in the power grid are presented and analyzed in detail in terms of their operation mechanism, construction and design, and advantages and disadvantages. The performance of LIBs in terms of the following grid services is highlighted: (1) frequency regulation; (2) peak shifting; (3) integration with renewable energy sources; and (4) power management. In addition, many challenges encountered in the application of LIBs are discussed, and possible research directions aimed at overcoming these challenges are provided to promote efforts in this area.

\section{Fundamental of LIBs}

LIBs have been commercially introduced by Sony since the early 1990s. To date, LIBs have been developed as one of the most important battery technologies dominating the market [22]. Generally, LIB technology is based on lithiumintercalation compounds. As shown in the schematic of LIBs (Fig. 1 [23]), lithium ions migrate through the electrolyte that is located between anode and cathode. During the discharge process, lithium ions are readily released from the anode and diffused into the delithiated cathode, which are related to the oxidation and reduction of two electrodes, respectively [5, 24].

\section{Anodes}

Typically, in LIBs, anodes are graphite-based materials because of the low cost and wide availability of carbon. Moreover, graphite is common in commercial LIBs because of its stability to accommodate the lithium insertion. The low thermal expansion of LIBs contributes to their stability to maintain their discharge/charge capacity even after long discharge/charge cycles. However, the capacity of graphite to accommodate the lithium insertion $(372 \mathrm{mAh} / \mathrm{g})$ is relatively low, and LIBs will attract more attention if this property is improved [25]. Fortunately, in recent years, considerable efforts have been exerted to optimize anode materials based on graphite, and several new anode materials, including silicon, alloy, and metal oxides, are developed [26-29]. The capacity and lifetime of commercial LIBs have been effectively improved through the development of novel anode materials (e.g., silicon/carbon composite) or new nickel-rich cathode materials [30].

\section{Cathodes}

The name of current commercial LIBs originated from the lithium-ion donator in the cathode, which is the major determinant of battery performance. Generally, cathodes consist of a complex lithiated compound material, particularly several lithium metal oxide materials, such as $\mathrm{LiCoO}_{2}$, $\mathrm{LiMn}_{2} \mathrm{O}_{4}$, and $\mathrm{LiFePO}_{4}$ [31-33]. With different cathodes, battery performance significantly differs. However, compared with metallic lithium, all of the aforementioned compounds show high impedance because of their low diffusion coefficients and ionic conductivities, which will result in low $\mathrm{EE}$ and lifetime. This limitation can be overcome by fabricating the cathode from finely powdered lithium compound 
Fig. 1 A schematic illustration of the working principle of LIBs based on the $\mathrm{Li}_{x} \mathrm{C}_{6} / \mathrm{Li}_{1-x} \mathrm{CoO}_{2}$ cathode. During the discharging process, lithium ions are released from a lithiated graphite $\left(\mathrm{Li}_{x} \mathrm{C}_{6}\right)$ anode to a delithiated $\mathrm{Li}_{1-x} \mathrm{CoO}_{2}$ cathode. During the charging process, the reaction is reversed. Reproduced with permission [23]. Copyright 2012, The Royal Society of Chemistry

\section{How Lithium-Ion Batteries Work}

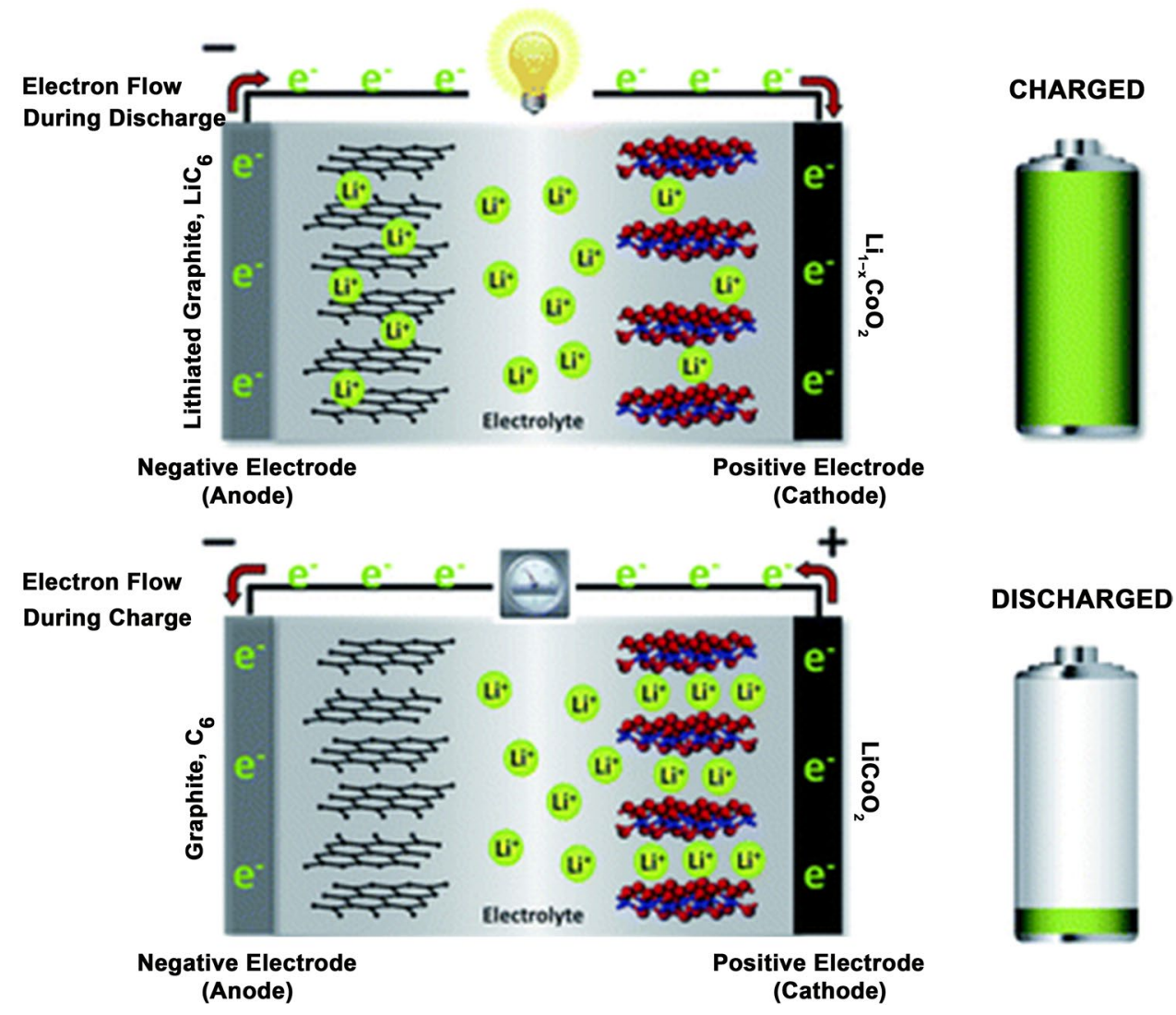

materials and blending with conductive materials (e.g., carbon) by mixing with a binder (e.g., polyvinylidene fluoride) and a solvent (e.g., $N$-methyl-2-pyrrolidone) [34]. The cathode on $\mathrm{Al}$ foil is formed into plate or spiral shape.

\section{Electrolytes}

The electrolytes in LIBs are mainly divided into two categories, namely liquid electrolytes and semisolid/solid-state electrolytes. Usually, liquid electrolytes consist of lithium salts [e.g., $\mathrm{LiBF}_{4}, \mathrm{LiPF}_{6}, \mathrm{LiN}\left(\mathrm{CF}_{3} \mathrm{SO}_{2}\right)_{2}$, and $\mathrm{LiBOB}$ ], which are dissolved in organic carbonates (e.g., ethylene carbonate, propylene carbonate, ethyl methyl carbonate, dimethyl carbonate, and their mixtures) [35]. Typically, the semisolid/ solid-state electrolytes are composed of lithium salts as the conducting salts and high-molecular-weight polymer matrices (e.g., polyvinylidene fluoride, poly(ethylene oxide), and polyvinylidene fluoride-hexafluoropropylene) $[36,37]$.

\section{Characteristics and Performance of LIBs}

As aforementioned, in the electrical energy transformation process, grid-level energy storage systems convert electricity from a grid-scale power network into a storable form and convert it back into electrical energy once needed. Energy storage systems in the power grid need to meet the balance of electricity demand and supply in the grid. Therefore, to comply with the applications to grid-level energy storage systems, gravimetric energy density needs to be considered [14]. High EE and long cycle life are also needed [38]. In addition, a low cost and safe battery module is critical for building a high-efficiency battery system in large-scale energy storage.

Generally, the types of commercial LIBs currently used are coin, cylindrical, prismatic, and pouch (Fig. 2 [39]). In most cases, cylindrical cells follow a standard model size, i.e., 18650 cells, such as those used in Tesla cars [40]. Typically, during assembly at high tension, 18650 cell batteries deliver a $20 \%$ higher volumetric energy density of up to $600-650 \mathrm{Wh} / \mathrm{L}$ than prismatic and pouch cells [41]. Although cylindrical cells show higher energy densities, prismatic and pouch cells are more widely used because of the reduced module-level dead volume and higher design freedom. In addition, compared with cylindrical cells, prismatic-type and pouch-type batteries can be easily customized for specific products.

Presently, commercially available LIBs are based on graphite anode and lithium metal oxide cathode materials 

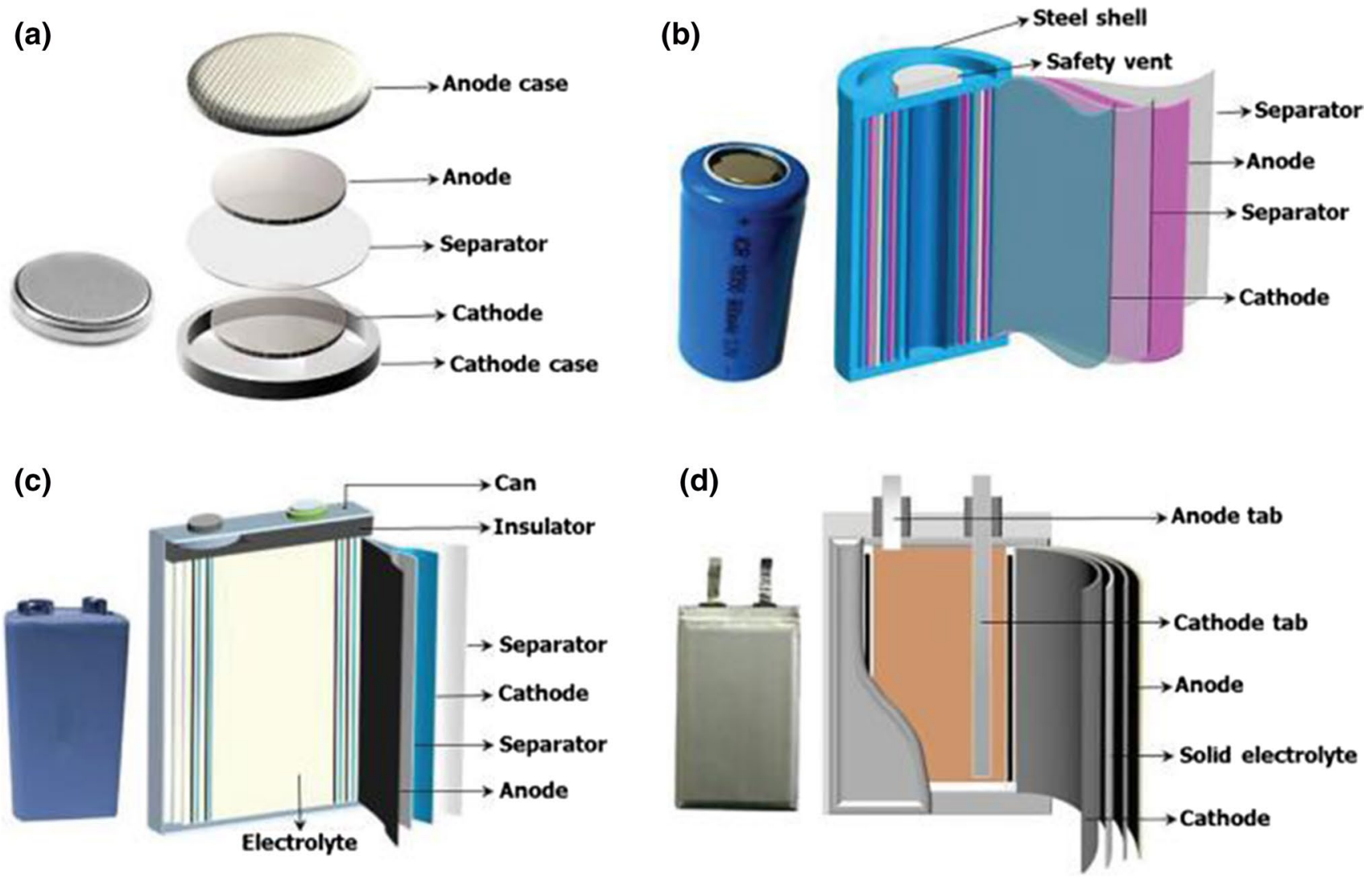

Fig. 2 Schematic of a coin-type, b cylindrical-type, c prismatic-type, d pouch-type batteries. Reproduced with permission [39]. Copyright 2019, Wiley

(e.g., $\mathrm{LiCoO}_{2}, \mathrm{LiFePO}_{4}$, and $\mathrm{LiMn}_{2} \mathrm{O}_{4}$ ), which exhibit theoretical capacities of $372 \mathrm{mAh} / \mathrm{g}$ and less than $200 \mathrm{mAh} / \mathrm{g}$, respectively [21]. However, state-of-the-art LIBs showing an energy density of 75-200 Wh/kg cannot provide sufficient energy for use in grid-level energy storage. To further improve the specific energy of LIBs, many alternatives to graphite with higher specific capacity are under exploration. For example, silicon shows high potential as a promising anode material that deliver a high theoretical capacity of $4200 \mathrm{mAh} / \mathrm{g}$ and attractive operating voltage (approximately $0.3 \mathrm{~V}$ vs. $\mathrm{Li} / \mathrm{Li}^{+}$) [21]. In previous work, on the basis of an anode of $50 \%$ replacement of graphite with commercial $\mathrm{SiO}_{x}$ and a cathode of $\mathrm{LiNi}_{0.8} \mathrm{Co}_{0.1} \mathrm{Mn}_{0.1} \mathrm{O}_{2}$ electrodes with high capacity, the energy density of a pouch-type battery configuration is predicted to increase by $7.6 \%$ [40]. Moreover, the cycle life of LIB is significantly attractive for use in grid-level energy storage as high as 10,000 cycles.

In addition to the cycle life described previously, the calendar life performance of LIBs needs to be analyzed when they are applied to grid-level energy storage systems where the maintenance or replacement of batteries demand a high cost. Calendar life refers to both the storage duration and the periodical discharge test, which should also be considered as it causes the capacity loss of the battery by self-discharging [42]. In 2017, Kubiak et al. [43] investigated the effects of self-discharging after a 3-year standby field deployment of a $250 \mathrm{~kW} / 500 \mathrm{kWh}$ LIB integrated with the grid and solar farm under the harsh climate conditions of Qatar. After testing, the residual capacity of LIB stack was evaluated to $93 \%$ of its initial available capacity, indicating its potential. However, it should be noted that several battery units have been damaged by self-discharging. Capacity decrease and power fading originate from the electrodes and electrolytes and the interfacial matching between them. For the electrodes, the dominant mechanism is as follows [44]: (1) contact loss of active material particles and decomposition of electrode materials (e.g., binder and additives) due to volume changes during cycling; (2) continuous solid-electrolyte interface (SEI) formation and growth leads to impedance increase at the electrodes; and (3) reactions of lithium with electrodes leading to the loss of mobile lithium. With respect to the electrolytes, electrolyte decomposition is the major cause for capacity loss, resulting in metal dissolution, migration of soluble species, precipitation of new phases, gas evolution, and surface layer formation. Moreover, the storage temperature has a significant effect on the calendar life of LIBs. 
For example, Asakura et al. [45] investigated the capacity retention of LP10-type LIBs under float charging conditions. They observed a capacity loss of $30 \%$ in 12 months at $45{ }^{\circ} \mathrm{C}$ even under mild conditions. Therefore, ongoing efforts are desired for exploring the self-discharging mechanism and designing advanced electrodes and electrolytes to promote the practical use of LIBs in power grids.

As mentioned previously, several unwanted/parasitic reactions include SEI growth, electrolyte decomposition, and electrode dissolution during cycling of LIBs leading to capacity loss. Coulombic efficiency (CE), which is expressed as the ratio of the discharged capacity to the capacity necessary to charge the material/system, can be used to measure the reversibility of the redox reactions [46]. Typically, graphite-based anodes exhibit high initial CEs, i.e., in the range of 95-99\%. Analogous to CE, EE, which represents the ratio of the discharge energy to the charge energy, is also a key performance indicator of LIBs because electrical energy can transform into another form of energy, such as thermal energy. Meister et al. [46] analyzed the CE and EE of different anode materials. The comparison of the intercalation/insertion materials graphite and soft carbon shows nearly comparable values for CE. After the first formation cycles, the CE increases to approximately $100 \%$. With respect to EE, graphite and soft carbon show the values of 93.8\% and $93.0 \%$, respectively. In addition, the lithium-rich cathode materials exhibit high $\mathrm{CE}$ and $\mathrm{EE}$ of approximately $99 \%$ and more than $90 \%$, respectively, surpassing other competitive battery systems (e.g., lead-acid and nickel metal hydride batteries). In practical use, low EE will be reflected by high extra energy costs, particularly for grid-level energy storage. Therefore, LIBs with high efficiency, long cycle life, low self-discharge, and high specific energy are promising for grid power supply.

Although LIBs dominate the market, they also encounter serious challenges in realizing their wide-scale use. The major limitation is their high cost, which can be attributed to the scarcity of lithium metal resources, specific packaging, and internal protection circuits preventing overcharge [1]. Measuring the lifetime cost (in $\$ / \mathrm{kWh}$ ) to understand the system economics is critical. To calculate the lifetime cost, the sum of the battery, installation, and transportation costs can be multiplied by the number of times that a new system is required over the project period, including the original install. Albright et al. [47] analyzed the lifetime cost of LIBs with the battery cost of approximately $\$ 600 / \mathrm{kWh}$, installation cost of approximately $\$ 3.6 / \mathrm{kWh}$, and transportation cost of approximately $\$ 5 / \mathrm{kWh}$. Many efforts have been exerted to reduce the manufacturing cost of LIBs to capture future energy markets. In the USA, a project to design and construct LIBs as an energy storage system for providing power in grid-connected micro turbine applications has been sponsored by the Department of
Energy and SAFT and SatCon Power Systems [1]. Moreover, a previous study reported that a demand of $100 \mathrm{GWh}$ is expected with a cost level of approximately $100 € / \mathrm{kWh}$ for stationary storage by 2025 [48].

In addition, LIBs are composed of highly active materials that are in contact with a flammable organic electrolyte. When they are subjected to conditions that are improperly designed, LIBs will fail prematurely. In particular, the reactions of charged positive and negative electrodes with electrolytes at elevated temperature easily result in incidents and safety issues. A previous work [49] showed that all of these materials begin reacting with the electrolyte at approximately $80^{\circ} \mathrm{C}$ at a low rate, which explains the phenomenon that LIBs begin to lose capacity when cycled at temperatures higher than $60{ }^{\circ} \mathrm{C}$. As the temperature increases, the reaction rate increases considerably. Moreover, any irregular use, such as disposing in unsafe environment with fire, excessive charging or discharging (e.g., overcharging and external short circuiting), and crushing, will result in spontaneous heat-evolving reactions, which can trigger fire or even an explosion [50]. Therefore, LIBs must pass a number of safety tests before they can be certified for use in grid-scale energy storage. The safety test must include electrical (e.g., short circuit and abnormal discharging and charging), mechanical, and environmental tests (e.g., temperature and altitude), which help determine the performance limits and ensure the working safety of LIBs.

\section{Applications of LIBs in Grid-Level Energy Storage Systems}

The grid-level energy storage system plays a critical role in the usage of electricity, providing electrical energy for various and large-scale deployment applications. The demand for electrical power varies daily, seasonally, and even emergently. Moreover, a large peak-to-valley difference between day and night can be observed. Therefore, storing the generated power and providing vacant power during peak load by peak shaving and load leveling are necessary. In addition, the renewable energy sources are susceptible to geological, seasonal, and temporal conditions. The intermittent nature leads to unpredictable fluctuations of output power, which cannot meet the demand for application to the electrical grid directly. Therefore, the power grid system needs to smooth the intermittent output power generated from renewable energy sources and reduce the fluctuations caused by renewable energy sources, such as wind and solar energy, by adjusting their output profiles. 


\section{Frequency Regulation and Peak Shaving}

For frequency regulation services, most projects have been reported to have a nominal power of more than $1 \mathrm{MW}$ and a power/energy ratio of approximately 1:1 [14]. Moreover, frequency regulation requires a fast response, high rate performance, and high power capability for the energy storage system, which is challenging for batteries. To provide stable and reliable power in large-scale deployment and islanded applications, the stability of the voltage and frequency should be considered. When there is a mismatch between power generation and utilization, energy storage systems can maintain the stability of the voltage and frequency of power supply for short-term and long-term applications. In terms of their high round-trip efficiency and energy density, LIBs exhibit considerable potential for application [51]. A LIB energy storage system has been constructed and operated commercially with a power of $8 \mathrm{MW} / 2 \mathrm{MWh}$ in 2010, which is increased to $16 \mathrm{MW}$ in 2011 in New York for frequency regulation services [52].

With respect to the application of LIBs to peak shaving services (Fig. 3 [53]), the power sizes vary between $10 \mathrm{kWh}$ and several MWh. Such high variations in practical applications are attributed to the highly specific demands of a wide range of customers. Mitsubishi Heavy Industries has installed a $1 \mathrm{MW}$ and $400 \mathrm{kWh}$ battery based on the combination of nickel, manganese, and cobalt, which is used for peak shaving and load leveling in wind farms and solar-power-connected energy storage systems [54]. In addition, the LIB energy storage system has been proposed for use in a newly designed DC line interactive UPS because of the high rate pulse discharge capability of LIBs (up to $10 \mathrm{C}$ for less than $10 \mathrm{~s}$ ), which is attractive for load leveling service in the $150 \mathrm{kVA}$ UPS system of a medical imaging machine. The proposed system has two modules that consist of $54 \mathrm{LIBs}$, each providing $170 \mathrm{~V}$ and pulsed peak (less than $5 \mathrm{~s}$ ) power of $75 \mathrm{~kW}[55,56]$.

Characterized by high discharge/charge efficiency, high specific energy, and long cycle life, LIBs based on electrochemistry represent a highly attractive energy storage technology to satisfy grid-level application needs.

\section{Renewable Energy Integration}

Given its abundance and wide distribution, renewable sources have become one of the most cost-effective choices for power generation in power grids in many regions [57]. In recent years, the substantial growth of variable renewable sources promotes the development of electrical energy storage systems and requires them to be more flexible. Battery energy storage systems can effectively store the generated electricity of renewable sources, contributing to grid system stability and reliability, which in turn promote the use of renewable energy sources [58].

Wind power generation represents one of the main renewable energy sources. However, given that it is strongly influenced by the season and geographical location, wind power generation considerably suffers from intermittence. Moreover, mismatch between peak power generation and demand is often observed. Storing the excess energy produced by wind farms to supply electrical energy when the power demand reaches its peak is an effective solution. Diouf and Pode [59] highlighted the future prospects of LIBs that serve as the major energy storage system in grid-level power stations integrated with renewable energy sources. Moreover, a company installed a LIB energy storage system with a power of $32 \mathrm{MW} / 8 \mathrm{MWh}$ (Laurel Mountain) to support the $98 \mathrm{MW}$ wind generation plant in New York in 2011 [60, 61]. In the UK, the largest European LIB energy storage pilot is in process. It will deploy a LIB system with a power
Fig. 3 Peak load shaving using an energy storage system. Reproduced with permission [53]. Copyright 2018, Elsevier

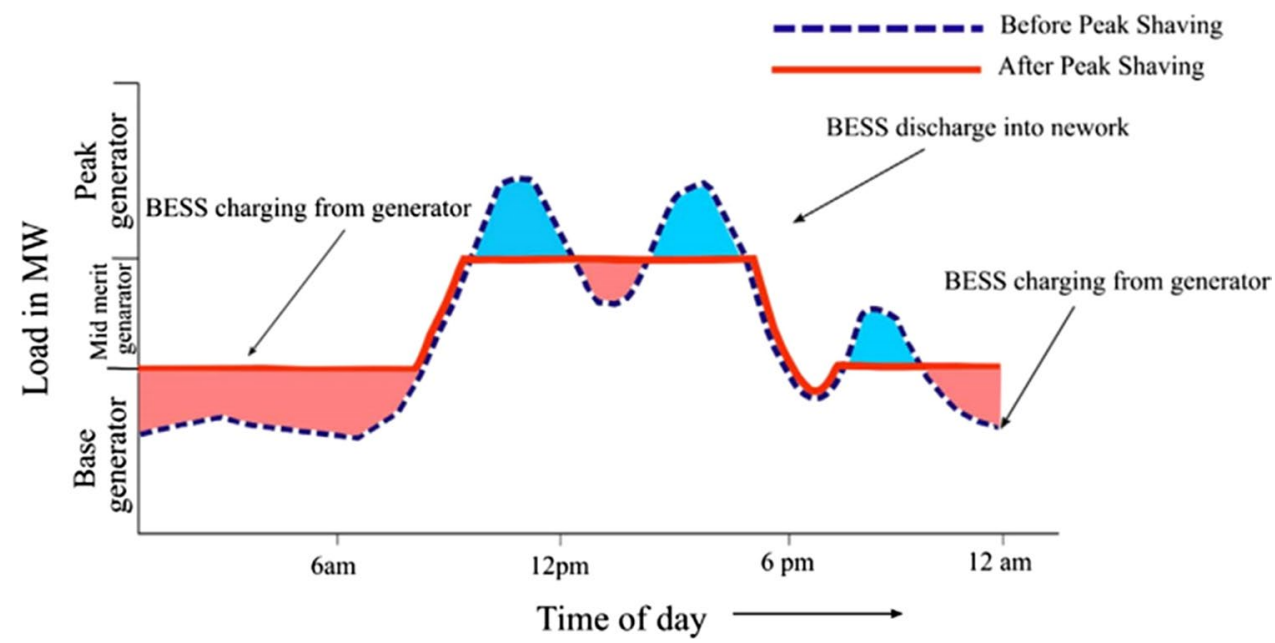


of $6 \mathrm{MW} / 10 \mathrm{MWh}$ at the primary substation, which can be effectively used to balance the intermittency of wind and other renewable energy sources [52, 62]. In addition, Toshiba launched a project that installs a $40 \mathrm{MW} / 20$ MWh LIB system in Tohoku, Japan, in December 2013 [63]. All of these efforts contribute to promoting the integration of renewable energy into the grid.

Solar photovoltaic power farms can also benefit from the integrated LIBs for storing the electrical energy and smoothing the output power. One of the main challenges to solar photovoltaic power generation is intermittence during the night and during periods when sunlight is blocked. The combination with batteries forms a perfect operating system that can cope with high-gradient power spikes and steady-state power requirements. Figure 4 depicts a grid-connected photovoltaic system based on the integrated energy storage system [64]. The use of batteries in a solar photovoltaic field exhibited output power stability, particularly under partial shading and solar radiation [65, 66]. Recently, Zubi et al. [34] pointed out that there will be continued growth of the LIB market with the integration of power supply systems with solar photovoltaics and wind power, which will be increased to $2 \mathrm{GWh} /$ year in 2020 and $30 \mathrm{GWh} /$ year in 2030.

\section{Power Management}

Generally, grid energy storage systems demand sufficient power and energy for their stable operation. To effectively drive the complex and wide-range devices in the grid, the number of power supplies should be large, in the order of hundreds and even thousands. Therefore, given the complex functionality and large-scale deployments of various devices in the grid, efficient power network management encounters serious challenges to ensure independent and cooperative work. The key hurdle is to design a power management system that can ensure long-term stability, reliable operation, work and storage safety, and cost-effectiveness. Moreover, when a large variety of batteries are packed in a stack, the power management service must balance the electrical characteristics (e.g., voltage and current) of each battery in the stack. The power management system is an essential contributor to the capability of the battery to satisfy the requirements of grid-level energy storage applications, which have a considerable effect on the operation of the overall battery stack and its safety and cost [12,67].

Although LIBs exhibit high energy density, one cell is insufficient to satisfy the requirements of the power grid. Therefore, the batteries need to be assembled in parallel to increase the current capability or in series to increase

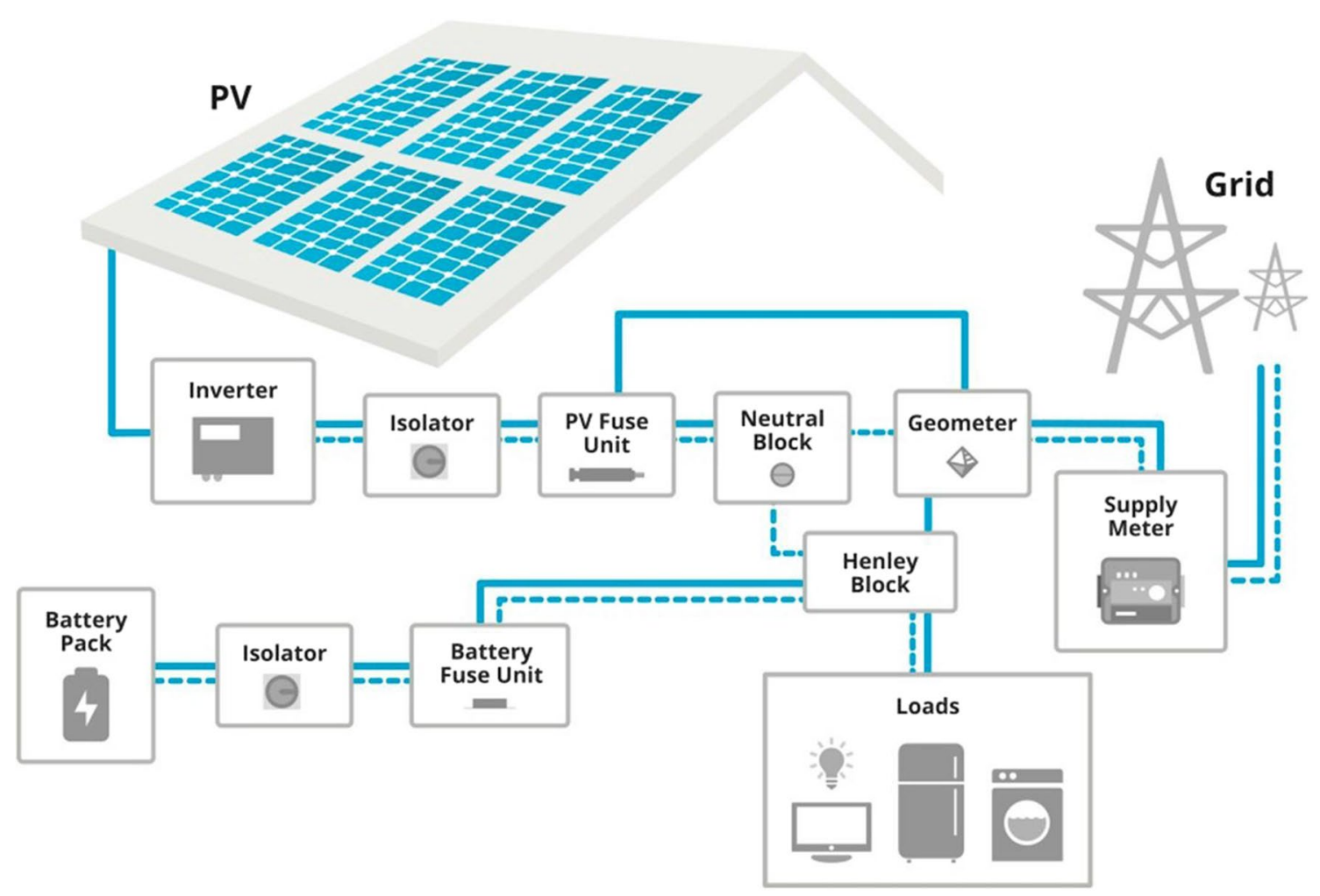

Fig. 4 Schematic diagram of a residential property system with static storage and photovoltaics. The solid lines indicate live connections, and the dashed lines indicate neutral connections. Reproduced with permission [64]. Copyright 2017, Elsevier 
the voltage, which poses serious challenges to the stability, voltage operation, safety, and cycle life. For example, with just a few cells in series, the charge current and voltage are divided nearly equally among the cells. However, to achieve a high voltage, many cells need to be connected in series, which will result in unevenly divided voltage among these cells, leading to unbalanced cells with some cells fully charged and others overcharged. LIBs do not deal well with overcharging, resulting in potential safety issues and limited cycle life of the system. Therefore, establishing a system monitor to prevent any cell from being overcharged and balance the batteries to maximize the performance of the entire system is essential.

To ensure safety, the LIB monitors must function as follows: (1) balance the circuit and prevent the voltage or current of any cell from exceeding the limit by stopping the charging current, which should be considered to address the safety issues and ensure the stability of the system, and (2) monitor the temperature and prevent the temperature of any cell from exceeding the limit by requesting that the system be stopped and cooled [67].

\section{Conclusions and Outlook}

In the twenty-first century, economic growth and social prosperity are more dependent on electrical energy than at any time before with a strong demand for a grid-level energy storage system. Characterized by modularization, rapid response, flexible installation, and short construction cycles, electrochemical batteries are considered to be the most attractive energy storage devices. In practical applications, battery systems need to meet the requirements of (1) frequency regulation; (2) peak shaving; (3) integration with renewable energy sources; and (4) power management. Among various energy storage technologies, LIBs have the potential to become a key component in achieving energy sustainability at the grid scale because of their high energy density, high EE, and long cycle life. In this perspective, the characteristics of LIBs for applications to grid-level energy storage systems are discussed. Moreover, the performances of LIBs in terms of the following grid services are highlighted: (1) frequency regulation; (2) peak shifting; (3) integration with renewable energy sources; and (4) power management.

Despite the potential of LIBs for application, several challenges with respect to their grid-scale applications that should be addressed to ensure substantial room for improvement and tremendous opportunities for application in different directions are as follows:

1. Decreasing cost further: Cost plays a significant role in the application of LIBs to grid-level energy stor- age systems. However, the use of LIBs in stationary applications is costly because of the potential resource limitations of lithium. Therefore, substantial cost reductions are required to enable ongoing accelerated market growth, particularly for its use in the power grid. In addition, high-performance and novel battery systems (e.g., potassium-ion and $\mathrm{Li}-\mathrm{S}$ batteries) need to be investigated $[68,69]$.

2. Building an effective LIB collection and recycling scheme: Establishing an effective and far-reaching LIB recovery and recycling scheme is important. The industry needs to successfully reduce the environmental impact of raw material extraction and battery disposal and to mitigate material bottlenecks and their price impacts to ensure ongoing accelerated market growth.

3. Exploring novel battery technologies: Research on grid-level energy storage system must focus on the improvement of battery performance, including operating voltage, EE, cycle life, energy and power densities, safety, environmental friendliness, and cost. Thus far, LIBs have exceeded other previously competitive battery types (e.g., lead-acid and nickel metal hydride batteries) but still need extensive and in-depth investigations to improve the energy density, reduce the cost, and develop safe battery systems. A large variety of post-LIB materials and systems that have a critical role in meeting power grid demands need to be developed, such as low cost multivalent batteries and high-energy-density metal-air batteries [70-73].

4. Establishing comprehensive assessment: An intelligent power grid integrates large-scale power sources and applications, which are distributed worldwide with different environmental conditions, temperatures, and geographical locations. The evaluation of battery performance should consider the technical properties (e.g., round-trip efficiency, lifetime, working voltage, and power and energy densities), cost, safety, and environmental impact. Moreover, using the same standards to evaluate and compare the performance of different battery technologies is important.

Open Access This article is licensed under a Creative Commons Attribution 4.0 International License, which permits use, sharing, adaptation, distribution and reproduction in any medium or format, as long as you give appropriate credit to the original author(s) and the source, provide a link to the Creative Commons licence, and indicate if changes were made. The images or other third party material in this article are included in the article's Creative Commons licence, unless indicated otherwise in a credit line to the material. If material is not included in the article's Creative Commons licence and your intended use is not permitted by statutory regulation or exceeds the permitted use, you will need to obtain permission directly from the copyright holder. To view a copy of this licence, visit http://creativecommons.org/licenses/by/4.0/. 


\section{References}

1. Chen HS, Cong TN, Yang W et al (2009) Progress in electrical energy storage system: a critical review. Prog Nat Sci 19(3):291-312

2. Lu C, Xu HC, Pan X et al (2014) Optimal sizing and control of battery energy storage system for peak load shaving. Energies 7(12):8396-8410

3. Wen GH, Hu GQ, Hu JQ et al (2016) Frequency regulation of source-grid-load systems: a compound control strategy. IEEE Trans Ind Inf 12(1):69-78

4. Breban S, Ansel A, Nasser M et al (2007) Experimental results on a variable-speed small hydro power station feeding isolated loads or connected to power grid. In: International Aegean conference on electrical machines and power electronics 2007. IEEE, Bodrum, pp 760-765

5. Dunn B, Kamath H, Tarascon J-M (2011) Electrical energy storage for the grid: a battery of choices. Science 334(6058):928-935

6. Doucette RT, McCulloch MD (2011) A comparison of high-speed flywheels, batteries, and ultracapacitors on the bases of cost and fuel economy as the energy storage system in a fuel cell based hybrid electric vehicle. J Power Sources 196(3):1163-1170

7. Hamsic N, Schmelter A, Mohd A et al (2007) Increasing renewable energy penetration in isolated grids using a flywheel energy storage system. In: 2007 international conference on power engineering-energy and electrical drives. IEEE, Setubal, pp 195-200

8. Madlener R, Latz J (2013) Economics of centralized and decentralized compressed air energy storage for enhanced grid integration of wind power. Appl Energy 101:299-309

9. Fan XY, Liu B, Liu J et al (2019) Battery technologies for gridlevel large-scale electrical energy storage. Trans Tianjin Univ. https://doi.org/10.1007/s12209-019-00231-w

10. Zhao BS, Ding YC, Wen ZH (2019) From jackfruit rags to hierarchical porous $\mathrm{N}$-doped carbon: a high-performance anode material for sodium-ion batteries. Trans Tianjin Univ 25(5):429-436

11. Crawford AJ, Huang Q, Kintner-Meyer MCW et al (2018) Lifecycle comparison of selected Li-ion battery chemistries under grid and electric vehicle duty cycle combinations. J Power Sources 380:185-193

12. Purvins A, Sumner M (2013) Optimal management of stationary lithium-ion battery system in electricity distribution grids. J Power Sources 242:742-755

13. Valant C, Gaustad G, Nenadic N (2019) Characterizing largescale, electric-vehicle lithium ion transportation batteries for secondary uses in grid applications. Batteries 5(1):8

14. Hesse HC, Schimpe M, Kucevic D et al (2017) Lithium-ion battery storage for the grid: a review of stationary battery storage system design tailored for applications in modern power grids. Energies 10(12):2107

15. Cao ZJ, Liu HT, Huang WL et al (2019) Hydrogen bondingassisted synthesis of silica/oxidized mesocarbon microbeads encapsulated in amorphous carbon as stable anode for optimized/enhanced lithium storage. Trans Tianjin Univ. https://doi. org/10.1007/s12209-019-00200-3

16. Guo L, Zhang S, Xie J et al (2020) Controlled synthesis of nanosized $\mathrm{Si}$ by magnesiothermic reduction from diatomite as anode material for Li-ion batteries. Int J Miner Metall Mater 27:1-11

17. Yuan CD, Zhang L, Li HC et al (2019) Highly selective lithium ion adsorbents: polymeric porous microsphere with crown ether groups. Trans Tianjin Univ 25(2):101-109

18. Alias N, Mohamad AA (2015) Advances of aqueous rechargeable lithium-ion battery: a review. J Power Sources 274:237-251

19. Etacheri V, Marom R, Elazari R et al (2011) Challenges in the development of advanced Li-ion batteries: a review. Energy Environ Sci 4(9):3243-3262
20. Lu LG, Han XB, Li JQ et al (2013) A review on the key issues for lithium-ion battery management in electric vehicles. J Power Sources 226:272-288

21. Su X, Wu QL, Li JC et al (2014) Silicon-based nanomaterials for lithium-ion batteries: a review. Adv Energy Mater 4(1):1300882

22. Vincent CA (2000) Lithium batteries: a 50-year perspective, 1959-2009. Solid State Ionics 134(1-2):159-167

23. Thackeray MM, Wolverton C, Isaacs ED (2012) Electrical energy storage for transportation-approaching the limits of, and going beyond, lithium-ion batteries. Energy Environ Sci 5(7):7854-7863

24. Hannan MA, Lipu MSH, Hussain A et al (2017) A review of lithium-ion battery state of charge estimation and management system in electric vehicle applications: challenges and recommendations. Renew Sustain Energy Rev 78:834-854

25. de las Casas C, Li WZ (2012) A review of application of carbon nanotubes for lithium ion battery anode material. J Power Sources 208:74-85

26. Ji LW, Lin Z, Alcoutlabi M et al (2011) Recent developments in nanostructured anode materials for rechargeable lithium-ion batteries. Energy Environ Sci 4(8):2682-2699

27. Sun XJ, Shao CZ, Zhang F et al (2018) SiC nanofibers as long-life lithium-ion battery anode materials. Front Chem 6:166

28. Wang LP, Chen G, Shen QX et al (2018) Direct electrodeposition of ionic liquid-based template-free SnCo alloy nanowires as an anode for Li-ion batteries. Int J Miner Metall Mater 25(9): 1027-1034

29. Xiong JW, Pan QC, Zheng FH et al (2018) N/S Co-doped carbon derived from cotton as high performance anode materials for lithium ion batteries. Front Chem 6:78

30. Shen XH, Tian ZY, Fan RJ et al (2018) Research progress on silicon/carbon composite anode materials for lithium-ion battery. J Energy Chem 27(4):1067-1090

31. Cao Q, Zhang HP, Wang GJ et al (2007) A novel carbon-coated $\mathrm{LiCoO}_{2}$ as cathode material for lithium ion battery. Electrochem Commun 9(5): 1228-1232

32. Huang YH, Goodenough JB (2008) High-rate $\mathrm{LiFePO}_{4}$ lithium rechargeable battery promoted by electrochemically active polymers. Chem Mater 20(23):7237-7241

33. Kim DK, Muralidharan P, Lee HW et al (2008) Spinel $\mathrm{LiMn}_{2} \mathrm{O}_{4}$ nanorods as lithium ion battery cathodes. Nano Lett 8(11):3948-3952

34. Zubi G, Dufo-López R, Carvalho M et al (2018) The lithium-ion battery: state of the art and future perspectives. Renew Sustain Energy Rev 89:292-308

35. Sasaki Y (2008) Organic electrolytes of secondary lithium batteries. Electrochemistry 76(1):2-15

36. Meyer WH (1998) Polymer electrolytes for lithium-ion batteries. Adv Mater 10(6):439-448

37. Prabhakar R, Kumar D (2019) Studies on polyacrylate-starch/ polyaniline conducting hydrogel. Curr Smart Mater 4(1):36-44

38. Fan XY, Liu XR, Hu WB et al (2019) Advances in the development of power supplies for the Internet of Everything. InfoMat 1(2):130-139

39. Liang YR, Zhao CZ, Yuan $\mathrm{H}$ et al (2019) A review of rechargeable batteries for portable electronic devices. Info Mat 1(1):6-32

40. Choi JW, Aurbach D (2016) Promise and reality of post-lithium-ion batteries with high energy densities. Nat Rev Mater 1(4):16013

41. Howard WF, Spotnitz RM (2007) Theoretical evaluation of highenergy lithium metal phosphate cathode materials in Li-ion batteries. J Power Sources 165(2):887-891

42. Ramasamy RP, White RE, Popov BN (2005) Calendar life performance of pouch lithium-ion cells. J Power Sources 141(2):298-306 
43. Kubiak P, Cen ZH, López CM et al (2017) Calendar aging of a $250 \mathrm{~kW} / 500 \mathrm{kWh}$ Li-ion battery deployed for the grid storage application. J Power Sources 372:16-23

44. Vetter J, Novák P, Wagner MR et al (2005) Ageing mechanisms in lithium-ion batteries. J Power Sources 147(1-2):269-281

45. Asakura K, Shimomura M, Shodai T (2003) Study of life evaluation methods for Li-ion batteries for backup applications. J Power Sources 119-121:902-905

46. Meister P, Jia HP, Li J et al (2016) Best practice: performance and cost evaluation of lithium ion battery active materials with special emphasis on energy efficiency. Chem Mater 28(20):7203-7217

47. Albright G, Edie J, Al-Hallaj S (2012) A comparison of lead acid to lithium-ion in stationary storage applications. All Cell Technologies LLC, New York

48. Nedjalkov A, Meyer J, Göken H et al (2019) Blueprint and implementation of rural stand-alone power grids with second-life lithium ion vehicle traction battery systems for resilient energy supply of tropical or remote regions. Materials 12(16):2642

49. MacNeil DD, Larcher D, Dahn JR (1999) Comparison of the reactivity of various carbon electrode materials with electrolyte at elevated temperature. J Electrochem Soc 146(10):3596-3602

50. Balakrishnan PG, Ramesh R, Prem KT (2006) Safety mechanisms in lithium-ion batteries. J Power Sources 155(2):401-414

51. Mehr TH, Masoum MAS, Jabalameli N (2013) Grid-connected lithium-ion battery energy storage system for load leveling and peak shaving. In: 2013 Australasian universities power engineering conference (AUPEC). IEEE, Hobart, pp 1-6

52. Kim J, Suharto Y, Daim TU (2017) Evaluation of electrical energy storage (EES) technologies for renewable energy: a case from the US Pacific Northwest. J Energy Storage 11:25-54

53. Uddin M, Romlie MF, Abdullah MF et al (2018) A review on peak load shaving strategies. Renew Sustain Energy Rev 82:3323-3332

54. Mukai D, Kobayashi K, Kurahashi T et al (2012) Development of large high-performance lithium-ion batteries for power storage and industrial use. Mitsubishi Heavy Ind Tech Rev 49(1):6

55. Hamidi SA (2017) DC line-interactive uninterruptible power supply (UPS) with load leveling for constant power and pulse loads. Dissertation, University of Wisconsin-Milwaukee, USA

56. Hamidi SA, Manla E, Nasiri A (2015) Li-ion batteries and Li-ion ultracapacitors: characteristics, modeling and grid applications. In: 2015 IEEE energy conversion congress and exposition, ECCE 2015, Montreal, pp 4973-4979

57. Wang YP, Ni CL, Shi YQ et al (2018) Experimental study on a modified wind-solar hybrid system. Trans Tianjin Univ 24(1):59-65

58. Liu XR, Yuan YF, Liu J et al (2019) Utilizing solar energy to improve the oxygen evolution reaction kinetics in zinc-air battery. Nat Commun 10:1-10

59. Diouf B, Pode R (2015) Potential of lithium-ion batteries in renewable energy. Renew Energy 76:375-380

60. Subburaj AS, Kondur P, Bayne SB et al (2014) Analysis and review of grid connected battery in wind applications. In: 2014 6th annual IEEE green technologies conference. Corpus Christi, pp 1-6

61. Taylor P, Bolton R, Stone D et al (2012) Pathways for energy storage in the UK: a report for the centre for low carbon futures. The Centre for Low Carbon Futures, New York

62. Luo X, Wang JH, Dooner M et al (2015) Overview of current development in electrical energy storage technologies and the application potential in power system operation. Appl Energy 137:511-536

63. Daly J (2014) Japan looks at recycling vehicle batteries for renewable power. http://oilprice.com/Alternative-Energy/RenewableEnergy/Japan-Looks-at-Recycling-Vehicle-Batteries-for-Renew able-Power.html. Accessed 1 May 2016

64. Uddin K, Gough R, Radcliffe J et al (2017) Techno-economic analysis of the viability of residential photovoltaic systems using lithium-ion batteries for energy storage in the United Kingdom. Appl Energy 206:12-21

65. Dolara A, Lazaroiu GC, Leva S et al (2013) Experimental investigation of partial shading scenarios on PV (photovoltaic) modules. Energy 55:466-475

66. Qi Y, Jia HJ (2012) Improved voltage control strategy for photovoltaic grid-connected system based on double-layer coordination control. Trans Tianjin Univ 18(4):271-278

67. Davide A (2010) Battery management systems for large lithium ion battery packs. Artech House, Norwood

68. Din MMUD, Ramakumar S, Indu MS et al (2019) Advances in electrolytes for high capacity rechargeable lithium-sulphur batteries. Curr Smart Mater. https://doi.org/10.2174/240546580466619 0617114914

69. Ding J, Zhang HL, Zhou H et al (2019) Sulfur-grafted hollow carbon spheres for potassium-ion battery anodes. Adv Mater 31(30): 1900429

70. Fan XY, Liu J, Song ZS et al (2019) Porous nanocomposite gel polymer electrolyte with high ionic conductivity and superior electrolyte retention capability for long-cycle-life flexible zinc-air batteries. Nano Energy 56:454-462

71. Li YB, Fu J, Zhong C et al (2019) Recent advances in flexible zinc-based rechargeable batteries. Adv Energy Mater 9(1):1802605

72. Sun YT, Liu XR, Jiang YM et al (2019) Recent advances and challenges in divalent and multivalent metal electrodes for metal-air batteries. J Mater Chem A 7(31):18183-18208

73. Zhao ZQ, Fan XY, Ding J et al (2019) Challenges in zinc electrodes for alkaline zinc-air batteries: obstacles to commercialization. ACS Energy Lett 4(9):2259-2270

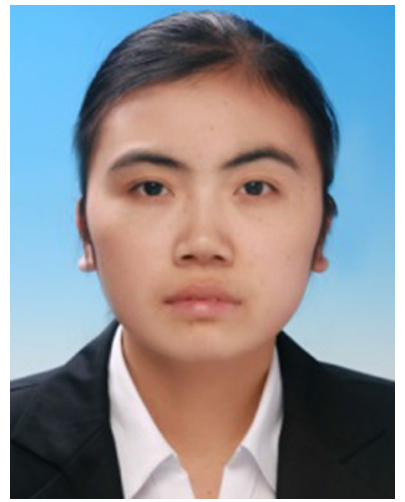

Tianmei Chen is currently engaged in Material Management at State Grid Zhejiang Zhedian Tendering Consulting Co., Ltd. She was born in March 1990. She received her master's degree from North China Electric Power University in 2014. 